\title{
Spontaneous obliteration of a dural arteriovenous fistula after treatment of polycythemia in a patient with Factor $V$ Leiden mutation: case report
}

\author{
J. van Beijnum • C. J. M. Klijn • T. H. Lo • \\ A. van der Zwan $\cdot$ L. J. Kappelle
}

Received: 18 January 2010/Revised: 10 March 2010/Accepted: 24 March 2010/Published online: 10 April 2010

(C) The Author(s) 2010. This article is published with open access at Springerlink.com

Dear Sirs,

A 62-year-old man experienced sudden shaking and dysesthesia of the right arm that lasted about $5 \mathrm{~min}$. Several hours later, he developed dysesthesia in the right hand that rapidly spread to his shoulder and right side of his face and tongue. After $10 \mathrm{~min}$, these symptoms disappeared completely. Four more similar events occurred in the following 2 weeks. A few months earlier, he had experienced three episodes with visual disturbances in his right hemifield that lasted $10 \mathrm{~min}$ and were followed by headache. His past medical history revealed myocardial infarction, renal insufficiency due to longstanding hypertension, hyperlipidemia, and polycythemia that was untreated for several years.

Neurological examination was normal. Laboratory investigations showed an increased hemoglobin (11.6 $\mathrm{mmol} / \mathrm{l}$, reference values $8.6-10.7 \mathrm{mmol} / \mathrm{l})$, increased hematocrit $(0.56$, reference values $0.41-0.50)$, and heterozygosity for Factor V Leiden (FVL). EEG revealed no signs of epilepsy. Subarachnoid hemorrhage was seen on CT (Fig. 1b). DSA showed a DAVF (Fig. 1c) with cortical reflux (Cognard grade 2b; Borden type II) $[1,3]$ and thrombosis of the superior sagittal sinus. Venesections were

J. van Beijnum ( $\varangle)$ · C. J. M. Klijn · L. J. Kappelle

Department of Neurology G03.124, University Medical Center Utrecht, PO Box 85500, 3508 GA Utrecht, The Netherlands e-mail: J.vanBeijnum@umcutrecht.nl

J. van Beijnum · A. van der Zwan

Department of Neurosurgery, University Medical Center Utrecht, PO Box 85500, 3508 GA Utrecht, The Netherlands

T. H. Lo

Department of Radiology, University Medical Center Utrecht, PO Box 85500, 3508 GA Utrecht, The Netherlands initiated resulting in normal hemoglobin $(10.2 \mathrm{mmol} / \mathrm{l})$ and hematocrit (0.50). No more attacks occurred afterwards.

Peroperative embolization using a burr hole directly above the fistula point was planned because tortuous feeders hampered a femoral approach and this combined approach was considered less invasive than neurosurgical occlusion. During the localizing DSA, the DAVF was found occluded with partial recanalization of the sinus (Fig. 1d-e). Follow-up MRI after 1 year showed no signs of recurrence of the fistula, a patent superior sagittal sinus, and obvious reduction of the dilated vessels (Fig. 1f).

DAVFs are one or more direct arteriovenous connections without intervening capillary bed. They are associated with trauma, cerebral venous sinus thrombosis (CVST), and thrombophilia $[4,8,14]$. Clinical outcome correlates with angiographic features. The retrograde flow into cortical veins in our patient is associated with a hemorrhage risk of $10 \%$ according to the Cognard classification [3]. Borden type II en III fistulas are associated with either progressive neurological deficits or hemorrhage [1].

Our case demonstrates that spontaneous obliteration of a DAVF can occur after treatment of polycythemia by venesections. The combination of polycythemia and heterozygosity for FVL had resulted in a prothrombotic state that probably caused gradual development of CVST and subsequent DAVF formation.

CVST commonly occurs in patients with a DAVF [14]. One hypothesis proposes opening of physiological arterialvenous shunts between meningeal arteries and venous sinuses due to increased venous pressure [7, 14]. A ratmodel suggests that venous hypertension may decrease cerebral perfusion which induces angiogenesis with subsequent development of a DAVF [9, 14]. In our patient venous pressure probably decreased after normalization of the blood viscosity. Finally, organization of a thrombus in a 
Fig. 1 T1-enhanced MR image shows multiple dilated intracranial and extracranial vessels (a). Non-enhanced CT scan shows subarachnoid hemorrhage especially in the right hemisphere (b). Diagnostic DSA shows a DAVF with arterial supply from medial meningeal and occipital arteries as well as cortical reflux (Cognard type IIb; Borden type II) (c). The subsequent localizing DSA shows no sign of the previous dural arteriovenous fistula (d) and partial recanalization of the superior sagittal sinus (e). Follow-up T1-enhanced MR image shows obvious reduction of the dilated vessels (f)
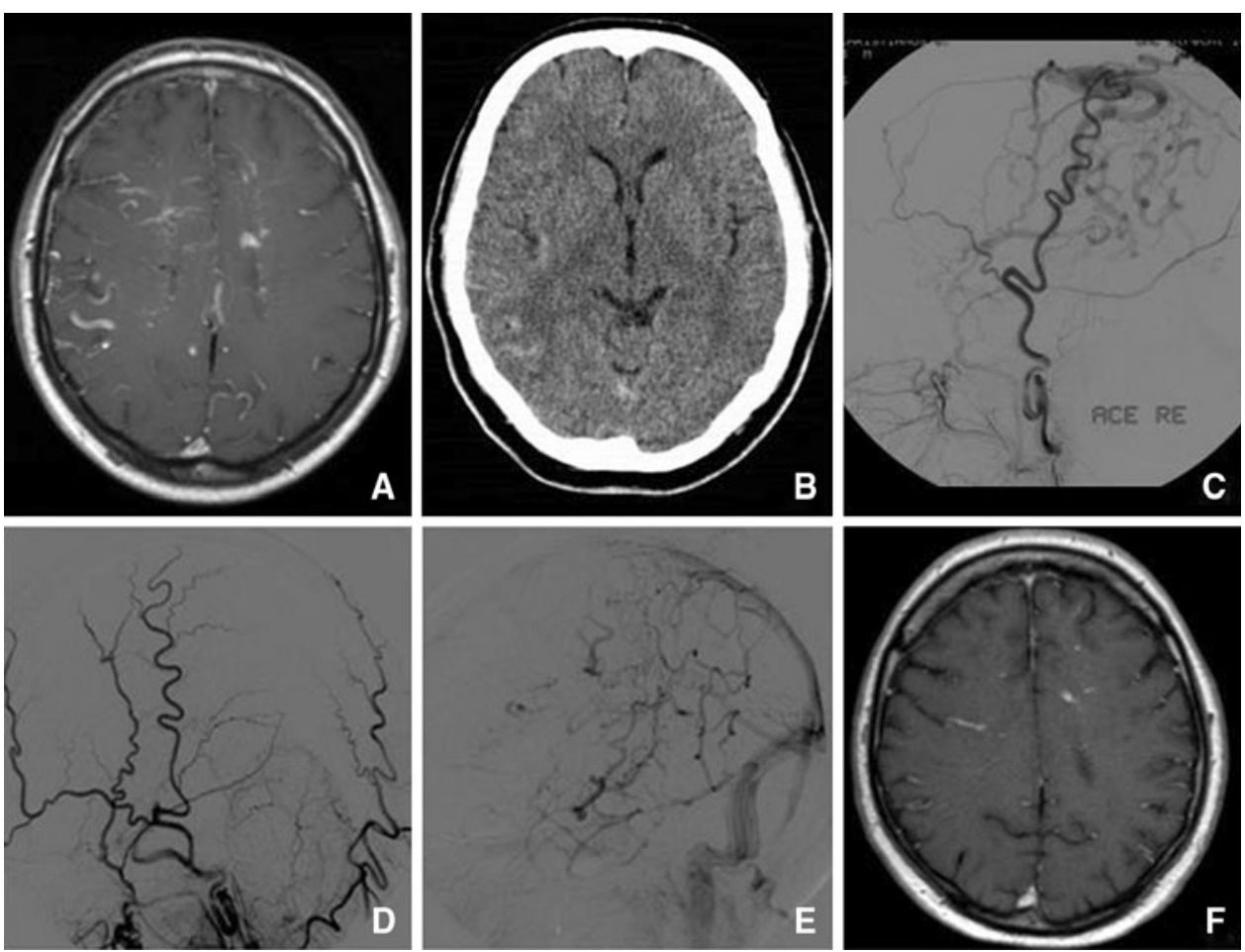

dural sinus may lead to "growth" of dural arteries that are normally present in sinus walls, which may result in a direct communication between artery and sinus [2].

FVL is a risk factor for CVST [12], but is also implicated in the pathogenesis of DAVFs [4, 8, 15]. Moreover, polycythemia is a risk factor for CVST [12], and these patients are prone to ischemic events probably because increased blood viscosity leads to decreased cerebral blood flow $[5,11]$. Venesections may increase flow in patients with polycythemia $[6,13]$.

Spontaneous obliteration of DAVFs has been described $[4,10]$. Possible mechanisms include recanalization of CVST, intracranial bleeding (with mass effect or vasospasm leading to obliteration), or intrinsic compression of the DAVF in the sinus wall [10]. Based on the observation in our patient, we suggest that in patients with polycythemia and DAVFs that have a relatively low risk of hemorrhage, polycythemia should be treated before interventional treatment, because venesections may lead to spontaneous closure of the DAVF.

Acknowledgments We thank W.G.H. Oerlemans MD for this contribution to this article. C.J.M. Klijn is supported by a grant from the Netherlands Heart Association (grant number 2007B048). Janneke van Beijnum was funded by the Netherlands Organization for Scientific Research (NWO) and the Netherlands Heart Foundation (grant number 2002B138).

Conflict of interest statement The authors report no conflict of interest.
Open Access This article is distributed under the terms of the Creative Commons Attribution Noncommercial License which permits any noncommercial use, distribution, and reproduction in any medium, provided the original author(s) and source are credited.

\section{References}

1. Borden JA, Wu JK, Shucart WA (1995) A proposed classification for spinal and cranial dural arteriovenous fistulous malformations and implications for treatment. J Neurosurg 82:166-179

2. Chaudhary MY, Sachdev VP, Cho SH, Weitzner I Jr, Puljic S, Huang YP (1982) Dural arteriovenous malformation of the major venous sinuses: an acquired lesion. AJNR Am J Neuroradiol $3: 13-19$

3. Cognard C, Gobin YP, Pierot L, Bailly AL, Houdart E, Casasco A, Chiras J, Merland JJ (1995) Cerebral dural arteriovenous fistulas: clinical and angiographic correlation with a revised classification of venous drainage. Radiology 194:671-680

4. Gerlach R, Yahya H, Rohde S, Bohm M, Berkefeld J, Scharrer I, Seifert V, Raabe A (2003) Increased incidence of thrombophilic abnormalities in patients with cranial dural arteriovenous fistulae. Neurol Res 25:745-748

5. Gumina RJ, Foley DA, Tefferi A, Rooke TW, Shields RC (2002) Polycythemia vera - a case report and discussion on pathogenic mechanisms of increased thrombosis. Angiology 53:587-591

6. Humphrey PR, du Boulay GH, Marshall J, Pearson TC, Russell RW, Symon L, Wetherley-Mein G, Zilkha E (1979) Cerebral blood-flow and viscosity in relative polycythaemia. Lancet 2:873-877

7. Kerber CW, Newton TH (1973) The macro and microvasculature of the dura mater. Neuroradiology 6:175-179

8. Kraus JA, Stuper BK, Muller J, Nahser HC, Klockgether T, Berlit $\mathrm{P}$, Harbrecht U (2002) Molecular analysis of thrombophilic risk 
factors in patients with dural arteriovenous fistulas. J Neurol 249:680-682

9. Lawton MT, Jacobowitz R, Spetzler RF (1997) Redefined role of angiogenesis in the pathogenesis of dural arteriovenous malformations. J Neurosurg 87:267-274

10. Luciani A, Houdart E, Mounayer C, Saint Maurice JP, Merland JJ (2001) Spontaneous closure of dural arteriovenous fistulas: report of three cases and review of the literature. AJNR Am J Neuroradiol 22:992-996

11. Semple PD, Lowe GD, Patterson J, Beastall GH, Rowan JO, Forbes CD, Hume R (1983) Comparison of cerebral blood flow after venesection of bronchitic secondary polycythaemic and primary polycythaemic patients. Scott Med J 28:332-337
12. Stam J (2005) Thrombosis of the cerebral veins and sinuses. N Engl J Med 352:1791-1798

13. Thomas DJ, du Boulay GH, Marshall J, Pearson TC, Ross Russell RW, Symon L, Wetherley-Mein G, Zilkha E (1977) Cerebral blood-flow in polycythaemia. Lancet 2:161-163

14. Tsai LK, Jeng JS, Liu HM, Wang HJ, Yip PK (2004) Intracranial dural arteriovenous fistulas with or without cerebral sinus thrombosis: analysis of 69 patients. J Neurol Neurosurg Psychiatry $75: 1639-1641$

15. van Dijk JM, terBrugge KG, Van der Meer FJ, Wallace MC, Rosendaal FR (2007) Thrombophilic factors and the formation of dural arteriovenous fistulas. J Neurosurg 107:56-59 